\title{
DIETARY HABIT OF MEDICAL STUDENTS- A STUDY AMONG THE STUDENTS OF A HEALTH UNIVERSITY IN EASTERN INDIA
}

\author{
Biswa Bhusan Mohanty1, Karmajeet Rath², Sunil Kumar Jena ${ }^{3}$, Gyana Ranjan Nayak, Saroj Kumar Patra ${ }^{5}$, Niranjan Sahoo ${ }^{6}$
}

${ }_{1}^{1}$ Associate Professor, Department of Anatomy, IMS and SUM Hospital, Bhubaneswar, Odisha, India.

${ }^{2}$ Associate Professor, Department of Pharmacology, IMS and SUM Hospital, Bhubaneswar, Odisha, India.

3Tutor, Department of Physiology, VIMSAR, Burla, Odisha, India.

${ }^{4}$ Associate Professor, Department of Anatomy, IMS and SUM Hospital, Bhubaneswar, Odisha, India.

${ }^{5}$ Associate Professor, Department of Orthopaedics, IMS and SUM Hospital, Bhubaneswar, Odisha, India.

${ }^{6}$ Assistant Professor, Department of FMT, IMS and SUM Hospital, Bhubaneswar, Odisha, India.

\section{BACKGROUND}

\section{ABSTRACT}

Diet is an important pillar of good health. A healthy diet is essential for every student, especially for medical students, as they are the budding doctors. Knowledge about healthy diet is essential for them as they are the one who guide their patients as well as the society about the importance of good eating habits.

Aim- To determine the dietary habits of medical students.

\section{MATERIALS AND METHODS}

A cross-sectional study was conducted among the medical students of a health university of Eastern India. The study included 278 students. A questionnaire was composed which contained questions regarding their dietary habits. Data collected was tabulated and analysed.

\section{RESULTS}

It was found that $51.3 \%$ male and $42.9 \%$ female students were taking daily breakfast. $82.9 \%$ of male and $61.9 \%$ of female students were taking regular meals and rest having irregular meals. Most of the male (53.9\%) and female (47.6\%) students were habituated to consume snacks in fast food centre. Other aspects of their diet pattern were also discussed.

\section{CONCLUSION}

The study showed that most of the students have healthy dietary habits with some lacunae present. The different factors responsible for it were determined. A better dietary knowledge is necessary for the students.

\section{KEY WORDS}

Healthy Diet, Medical Students, Cross-Sectional Study.

HOW TO CITE THIS ARTICLE: Mohanty BB, Rath K, Jena SK, et al. Dietary habit of medical students- a study among the students of a health university in Eastern India. J. Evolution Med. Dent. Sci. 2018;7(22):2698-2701, DOI: 10.14260/jemds/2018/608

\section{BACKGROUND}

The most important health issues faced by today's society are obesity and poor nutrition in terms of health as well as health expenses. ${ }^{1}$ The top three causes of death are diet related diseases like cardiovascular diseases, cancer and stroke. ${ }^{2}$ These diseases are strongly associated with unhealthy lifestyle habits like inappropriate nutrition, lack of exercise, smoking, alcohol consumption, caffeine overuse and improper sleeping habits. 3,4 Obesity results from a complex interaction between dietary factors and other environmental factors like genetic predisposition. It plays a vital role in development of other diseases like hypertension, type II DM and coronary artery disease. ${ }^{5}$ Healthy diet and nutrition are the basis of health and they are one of the main WHO and EFSA priorities (Ministry of Agriculture of the Czech Republic,

'Financial or Other Competing Interest': None.

Submission 10-04-2018, Peer Review 10-05-2018,

Acceptance 17-05-2018, Published 28-05-2018.

Corresponding Author:

Dr. Karmajeet Rath,

Associate Professor,

Department of Pharmacology,

IMS and SUM Hospital, K-8, Kalinga Nagar

Bhubaneswar-751003, Odisha, India.

E-mail: drkarmajeetrath@gmail.com

DOI: $10.14260 /$ jemds $/ 2018 / 608$
2010). However, during college life many students are exposed to stress and lack of time, both of which act as barrier to maintain healthy food habits. Unhealthy habits like lack of healthy diet, lack of exercise, improper sleep, intake of alcohol and smoking results in increased prevalence of chronic diseases. Healthy food habits are very important for students of medical college, as they are budding doctors who have the responsibility to guide other people about healthy dietary habits. Hence, this study was undertaken to determine the dietary habits of the medical students and to compare the results with other studies done at different regions of the world.

\section{MATERIALS AND METHODS}

This descriptive cross-sectional study was conducted among 278 medical students (152 males, 126 females) in Institute of Medical Sciences, Siksha 'O' Anusandhan University, Bhubaneswar by using stratified sampling technique. It was conducted during the period of May 2016 to June 2016. Ethical Committee approval was obtained from the Institutional Review Board. Purpose of the study was explained to the students and informed consent was obtained from each student. Students who were not willing to participate and who were absent are excluded from the study. The study was conducted using a standard questionnaire, which included 19 questions. The first part of 
the questionnaire contained some general data about the students like their age, sex, height and weight. The second part contained different questions regarding their food habits and the barrier that prevented them from maintaining a healthy dietary habit. In order to gain their confidence, the students are asked not to disclose their names. 300 questionnaires were distributed initially, out of which 283 questionnaires were returned back. Among the returned questionnaire, 5 were incomplete. The incompletely answered questionnaires were rejected. Finally, 278 questionnaires were selected as the subject for this study. The collected data were analysed using Statistical Package for Social Sciences (SPSS) version 16.00. Chi-square $\left(\chi^{2}\right)$ statistical test was used to examine significant distribution of subjects among different variables. $P$ value $\leq 0.05$ was considered to be significant. Generation of tables was done by Microsoft Word.

\section{RESULTS}

The data collected were tabulated and analysed. The results found are discussed below.

\begin{tabular}{|c|c|c|c|c|c|}
\hline Factors & Variables & Yes & No & $\chi^{2}$ & $\mathbf{P}$ \\
\hline \multirow{2}{*}{$\begin{array}{l}\text { Regularity } \\
\text { of meals }\end{array}$} & $M$ & $126(82.9 \%)$ & $26(17.1 \%)$ & \multirow{2}{*}{15.53} & \multirow{2}{*}{0.000} \\
\hline & $F$ & $78(61.9 \%)$ & $48(38.1 \%)$ & & \\
\hline \multirow{2}{*}{$\begin{array}{c}\text { Daily } \\
\text { breakfast }\end{array}$} & $\mathrm{M}$ & $78(51.3 \%)$ & $74(48.7 \%)$ & \multirow{2}{*}{1.97} & \multirow{2}{*}{0.160} \\
\hline & $\mathrm{F}$ & $54(42.9 \%)$ & $72(57.1 \%)$ & & \\
\hline
\end{tabular}

This table illustrates distribution of subjects among different variables for corresponding factor. Data analysis was done by Chi-square $\left(\chi^{2}\right)$ test. $\mathrm{P}<0.05$ was considered to be significant. Data is expressed in number and percentage form. M-Male, F-Female.

\begin{tabular}{|c|c|c|c|c|c|c|}
\hline Factor & $\mathbf{V}$ & $<3$ & 3 & $>3$ & $\chi^{2}$ & $\mathbf{P}$ \\
\hline \multirow{2}{*}{$\begin{array}{c}\text { Daily } \\
\text { number of meals }\end{array}$} & M & 70 (46.1\%) & $60(39.5 \%)$ & $22(14.4 \%)$ & \multirow{2}{*}{20.66} & \multirow{2}{*}{0.000} \\
\hline & $\mathrm{F}$ & $92(73 \%)$ & $24(19.1 \%)$ & $10(7.9 \%)$ & & \\
\hline \multirow{2}{*}{ Daily number of snacks } & $\mathrm{M}$ & $126(82.9 \%)$ & $10(6.6 \%)$ & $16(10.5 \%)$ & \multirow{2}{*}{9.17} & \multirow{2}{*}{0.010} \\
\hline & $\mathrm{F}$ & $116(92.1 \%)$ & $8(6.3 \%)$ & $2(1.6 \%)$ & & \\
\hline \multirow{2}{*}{ Weekly consumption of meats } & $\mathrm{M}$ & $24(15.8 \%)$ & $24(15.8 \%)$ & 92 & \multirow{2}{*}{43.78} & \multirow{2}{*}{0.000} \\
\hline & $\mathrm{F}$ & $44(34.9 \%)$ & $36(28.6 \%)$ & 22 & & \\
\hline \multirow{2}{*}{ Weekly consumption of vegetables } & $\mathrm{M}$ & $24(15.8 \%)$ & $30(19.7 \%)$ & $98(64.5 \%)$ & \multirow{2}{*}{36.06} & \multirow{2}{*}{0.000} \\
\hline & $\mathrm{F}$ & $62(49.2 \%)$ & $14(11.1 \%)$ & $50(39.7 \%)$ & & \\
\hline \multirow{2}{*}{ Weekly consumption of fruits } & $\mathrm{M}$ & $72(47.4 \%)$ & $32(21.1 \%)$ & $48(31.6 \%)$ & \multirow[b]{2}{*}{7.23} & \multirow{2}{*}{0.027} \\
\hline & $\mathrm{F}$ & $80(63.5 \%)$ & $18(14.3 \%)$ & $28(22.2 \%)$ & & \\
\hline \multirow{2}{*}{ Weekly consumption of dairy food } & $\mathrm{M}$ & $64(42.1 \%)$ & $20(13.2 \%)$ & $68(44.7 \%)$ & \multirow{2}{*}{30.22} & \multirow{2}{*}{0.000} \\
\hline & $\mathrm{F}$ & $86(68.2 \%)$ & $22(17.5 \%)$ & $18(14.3 \%)$ & & \\
\hline \multirow{2}{*}{ Weekly consumption of fried food } & M & $60(39.5 \%)$ & $28(18.4 \%)$ & $64(42.1 \%)$ & \multirow{2}{*}{5.13} & \multirow{2}{*}{0.077} \\
\hline & $\mathrm{F}$ & $54(42.9 \%)$ & $34(27 \%)$ & $38(30.1 \%)$ & & \\
\hline \multirow{2}{*}{ Weekly consumption of juice } & $\mathrm{M}$ & $70(46.1 \%)$ & $28(18.4 \%)$ & $54(35.5 \%)$ & \multirow{2}{*}{9.39} & \multirow{2}{*}{0.009} \\
\hline & $\mathrm{F}$ & $78(61.9 \%)$ & $10(7.9 \%)$ & $38(30.1 \%)$ & & \\
\hline
\end{tabular}

This table illustrates distribution of subjects among different variables for corresponding factor. Data analysis was done by Chisquare $\left(\chi^{2}\right)$ test. $\mathrm{P}<0.05$ was considered to be significant. Data is expressed in number and percentage form. V-Variables M-Male, F-Female.

\begin{tabular}{|c|c|c|c|c|c|c|c|}
\hline $\begin{array}{c}\text { Factor } \\
\text { Weekly consumption of } \\
\text { soft drink }\end{array}$ & Variable & $<3$ & 3 & $>3$ & Never & $\chi^{2}$ & $\mathbf{P}$ \\
\hline \multirow{2}{*}{$\begin{array}{l}\text { Weekly consumption of } \\
\text { soft drink }\end{array}$} & M & $64(42.1 \%)$ & 20 (13.2\%) & $66(43.4)$ & $2(1.3 \%)$ & \multirow{2}{*}{54.83} & \multirow{2}{*}{0.000} \\
\hline & $\mathrm{F}$ & $6(4.8 \%)$ & $36(28.6 \%)$ & $84(66.6)$ & 0 & & \\
\hline
\end{tabular}

This table illustrates distribution of subjects among different variables for corresponding factor. Data analysis was done by Chisquare $\left(\chi^{2}\right)$ test. $\mathrm{P}<0.05$ was considered to be significant. Data is expressed in number and percentage form. M-Male, F-Female.

\begin{tabular}{|c|c|c|c|c|c|c|c|c|}
\hline Factor & Variable & BF & Lunch & Snacks & Dinner & Never & $\chi^{2}$ & P \\
\hline Typically eat in & M & $4(2.6 \%)$ & $26(17.1 \%)$ & $82(53.9 \%)$ & $38(25 \%)$ & $2(1.3 \%)$ & \multirow{2}{*}{6.83} & 0.145 \\
\cline { 2 - 8 } FF centre & F Table 4. Male-Female comparison of Eating at Fast Food (FF) Centre \\
\hline \multicolumn{8}{|c|}{}
\end{tabular}

This table illustrates distribution of subjects among different variables for corresponding factor. Data analysis was done by Chisquare $\left(\chi^{2}\right)$ test. $\mathrm{P}<0.05$ was considered to be significant. Data is expressed in number and percentage form. M-Male, F-Female.

\begin{tabular}{|c|c|c|c|c|c|c|c|c|}
\hline Factor & Variable & $1-2 / w$ & $3-4 / w$ & $1 / d$ & $>1 / d$ & Never & $\chi^{2}$ & $\mathbf{P}$ \\
\hline \multirow{2}{*}{$\begin{array}{l}\text { Visit to fast } \\
\text { food centre }\end{array}$} & $\mathrm{M}$ & $82(53.9 \%)$ & $58(38.2 \%)$ & $8(5.2 \%)$ & $2(1.3 \%)$ & $2(1.3 \%)$ & \multirow{2}{*}{22.71} & \multirow{2}{*}{0.000} \\
\hline & $F$ & $96(76.2 \%)$ & $20(15.9 \%)$ & $4(3.2 \%)$ & 0 & $6(4.8 \%)$ & & \\
\hline
\end{tabular}

This table illustrates distribution of subjects among different variables for corresponding factor. Data analysis was done by Chisquare $\left(\chi^{2}\right)$ test. $P<0.05$ was considered to be significant. Data is expressed in number and percentage form. M-Male, F-Female. 


\begin{tabular}{|c|c|c|c|c|c|c|}
\hline Factor & Variable & $\begin{array}{c}<\mathbf{4} \\
\text { cups }\end{array}$ & $\begin{array}{c}\mathbf{4 - 8} \\
\text { cups }\end{array}$ & $\begin{array}{c}>\mathbf{8} \\
\text { cups }\end{array}$ & $\chi^{2}$ & P \\
\hline \multirow{2}{*}{$\begin{array}{c}\text { Daily water } \\
\text { intake }\end{array}$} & $\mathrm{M}$ & $\begin{array}{c}2 \\
(1.3 \%)\end{array}$ & $\begin{array}{c}48 \\
(31.6 \%)\end{array}$ & $\begin{array}{c}102 \\
(67.1 \%)\end{array}$ & \multirow{2}{*}{7.70} & \multirow{2}{*}{0.021} \\
\cline { 2 - 5 } & $\mathrm{F}$ & $\begin{array}{c}8 \\
(6.3 \%)\end{array}$ & $\begin{array}{c}54 \\
(42.9 \%)\end{array}$ & $\begin{array}{c}64 \\
(50.8 \%)\end{array}$ & & \\
\hline \multicolumn{7}{|c|}{ Table 6. Male-Female comparison of Daily Water Intake } \\
\hline
\end{tabular}

This table illustrates distribution of subjects among different variables for corresponding factor. Data analysis was done by Chi-square $\left(\chi^{2}\right)$ test. $\mathrm{P}<0.05$ was considered to be significant. Data is expressed in number and percentage form. M-Male, F-Female.

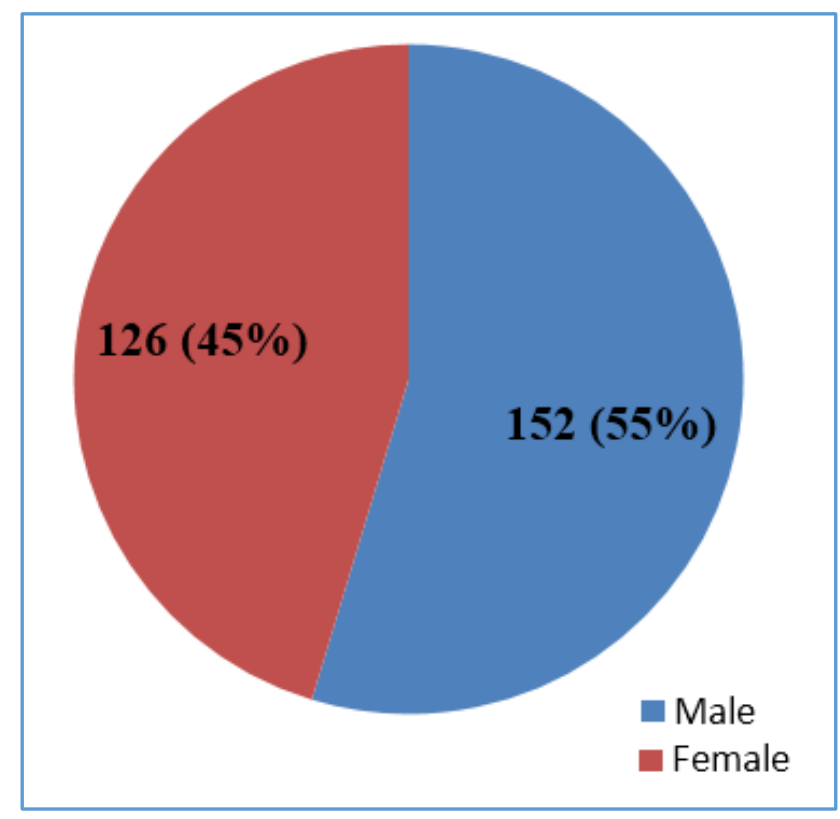

Figure 1. Distribution of Subjects

This figure shows the subjects according to gender. Data is expressed in number and percentage form.

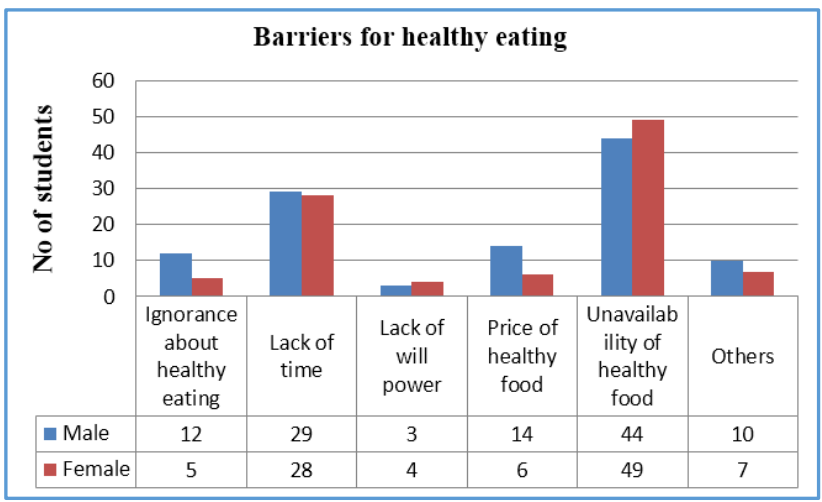

Figure 2. Barriers preventing the Students from Healthy Diet

This figure shows no. of students facing barrier for healthy eating.

This study was conducted among 278 students, which included 152 male and 126 female students as illustrated in Figure 1. Table 1 illustrates regularity of meals and daily breakfast of students. $82.9 \%$ of male and $61.9 \%$ of female students were taking regular meals and rest having irregular meals. $51.3 \%$ male and $42.9 \%$ female students were taking daily breakfast and rest were not. Table 2 illustrates frequency of diet patterns of students. Majority of male $(46.1 \%)$ and female $(73 \%)$ students were taking less than 3 meals daily. Majority of male (82.9\%) and female (92.1\%) students were taking less than 3 snacks daily. Majority of male $(60.5 \%)$ and female $(17.5 \%)$ students were consuming meat 3 times weekly. Majority of male (64.5\%) students were consuming vegetables more than 3 times weekly, while majority of female (49.2\%) students were consuming vegetables less than 3 times weekly. Majority of male (47.4\%) and female $(63.5 \%)$ students were consuming fruits less than 3 times weekly. Majority of male (44.7\%) students were consuming dairy foods more than 3 times weekly, while majority of female $(68.2 \%)$ students were consuming dairy foods less than 3 times weekly. Majority of male (42.1\%) students were consuming fried foods more than 3 times weekly, while majority of female $(42.9 \%)$ students were consuming fried foods less than 3 times weekly. Majority of male $(46.1 \%)$ and female $(61.9 \%)$ students were consuming juice less than 3 times weekly. Table 3 depicts weekly consumption of soft drinks. Majority of male (43.4\%) and female $(66.6 \%)$ students were consuming soft drinks more than 3 times weekly. Table 4 depicts fast food habit of students. Most of the male (53.9\%) and female (47.6\%) students were habituated to consume snacks in fast food centre. Table 5 depicts weekly visit to fast food centre. Most of male $(53.9 \%)$ and female $(76.2 \%)$ students visited fast food centre 1 - 2 times weekly. Table 6 depicts daily intake of water. Most of male (67.1\%) and female (50.8\%) students consume more than 8 cups of water daily. Figure 2 depicts the barriers, which affect the healthy eating of students.

There are many factors, which prevent the students from intake of a healthy diet shown in Figure 2 . It could be their ignorance $(12.2 \%)$, busy schedule $(41 \%)$, lack of will power (5\%), high price of healthy food $(7.9 \%)$ and unavailability of healthy food (67.4\%).

\section{DISCUSSION}

Regularity in the timing of meals is very important, because at that time secretion of gastric juice is highest, digestion is rapid, and appetite is better. ${ }^{6}$ From Table 1, it was found that $82.9 \%$ of males and $61.9 \%$ of females have regularity in their meals. It is better than the study conducted at Malaysian Medical School, which showed that $57.6 \%$ of students have regularity in their meals. ${ }^{7}$

A study done by Toschke et al showed that more frequent meals is associated with lower BMI. ${ }^{8}$ The study shows that only $14.4 \%$ of males and $7.9 \%$ of females have a frequency of taking meals more than thrice. It is lower than the study done by Ganasegeran et al, which had a result of $40.2 \%$ of students had meals at least thrice a day. ${ }^{7}$ The factors for this may be their ignorance about the study or the class schedule.

For medical students, long lasting energy is more essential due to their busy academic schedule. ${ }^{9}$ So, regular and heavy breakfast decreases the risk of getting fatigue. It was seen that $51.3 \%$ of males and $42.9 \%$ of females take their breakfast regularly, which is better than the study done by Ganasegeran et al which showed $43.9 \%$ of students had their breakfast regularly. ${ }^{7}$ 
Frequent consumption of snacks is a usual behaviour among teenage students. ${ }^{10}$ But the data in Table 2 shows that most of the males (82.9\%) and females (92.1\%) take snacks less than 3 times a day. So, the study shows that female students have better eating habits than males, which is in accordance with the study of Yahia et al. ${ }^{11}$ Still this finding is comparatively higher than previous studies done in different countries, which showed lesser proportion of Syrian adolescents $(53.0 \%)^{12}$ and Lebanon students $(53.2 \%)^{11}$ consumed snacks regularly.

Majority of males (64.5\%) have weekly consumption of vegetables more than 3 times, whereas majority of females (49.2\%) have weekly consumption of vegetables less than 3 times. In total $53.2 \%$ of students have a weekly consumption of vegetables more than 3 times, which is lower than the study conducted by Ganasegeran et al. ${ }^{7}$ In that study they have found the value to be $81.8 \%$. Also, frequent intake of vegetables is more in other countries like China (47.9\%) ${ }^{13}$ and less in Bahrain (26.3\%). ${ }^{12}$

Weekly consumption of fruit less than 3 times in males is predominant (47.4\%) as well as in females (63.5\%).

It is found that majority of males $(44.7 \%)$ have a better consumption of dairy products whereas in females the females have reluctance towards it (68.2\%).

Fried food consumption is more prevalent in males (42.1\%) than females (30.1\%). A study showed that frequent consumption of fried food results in higher BMI.14 So, 36.1\% of students are at the risk of increased BMI. However, this finding is lower than the study conducted by Ganasegeran et al, where $73.5 \%$ of students were found to be consuming fried foods more than twice a week. ${ }^{7}$

Rate of weekly consumption of juice is very poor among males $(46.1 \%)$ as well as females $(61.9 \%)$.

Frequent consumption of soft drinks increases the risk of obesity and type II diabetes mellitus. ${ }^{15}$ This study shows that $53.9 \%$ of students have a frequent intake of soft drink. This is lower than the study done by Abdalla Al-Haj et al (57\%) ${ }^{16}$ and higher than students of California State University survey done by Small et al (51.8\%). ${ }^{2}$ The incidence is higher among females $(66.6 \%)$ than males (43.4\%).

It is found that the students usually take all kinds of foods in fast food centres like breakfast, lunch, snacks as well as dinner. But usually they take snacks, which are more prevalent in males (53.9\%) as well as in females (47.6\%).

An active adult who lives in a warm environment need a daily water intake of 6 litres.17 But it varies from person to person according to the physical activity. $59.7 \%$ of students have a daily water intake of more than 8 cups a day, which is higher than the study of Ganasegeran et al (40\% had daily water intake of 2 litres or more). ${ }^{7}$

\section{CONCLUSION}

Dietary habits of the medical students were healthy, though some lacunae were present. Barriers for faulty dietary habits were discussed. Students should be educated properly about healthy eating, so that they can guide their patients properly in future.

\section{REFERENCES}

[1] Deshpande S, Basil MD, Basil DZ. Factors influencing healthy eating habits among college students: an application of the health belief model. Health Marketing Quart 2009;26(2):145-64.

[2] Small M, Bailey-Davis L, Morgan N, et al. Changes in eating and physical activity behaviors across seven semesters of college: living on or off campus matters. Health Educ Behav 2013;40(4):435-41.

[3] Eyre H, Kahn R, Robertson RM, et al. Preventing cancer, cardiovascular disease and diabetes: a common agenda for the American Cancer Society, the American Diabetes Association and the American Heart Association. Diabetes Care 2004;27(7):1812-24.

[4] Ignarro LJ, Balestrieri ML, Napoli C. Nutrition, physical activity and cardiovascular disease: an update. Cardiovasc Res 2007;73(2):326-40.

[5] Berenson GS, Bogalusa Heart Study Group. Health consequences of obesity. Pediatr Blood Cancer 2012;58(1):117-21.

[6] Škėmienè L, Ustinavičienè R, Piešinè $L$, et al. Peculiarities of medical students' nutrition. Medicina (Kaunas) 2007;43(2):145-52.

[7] Ganasegeran K, Al-Dubai SAR, Qureshi AM, et al. Social and psychological factors affecting eating habits among university students in a Malaysian medical school: a cross-sectional study. Nutr J 2012;11:48-55.

[8] Toschke AM, Küchenhoff $H$, Koletzko B, et al. Meal frequency and childhood obesity. Obesity Res 2005;13(11):1932-8.

[9] Tanaka M, Mizuno K, Fukuda S, et al. Relationships between dietary habits and the prevalence of fatigue in medical students. Nutrition 2008;24(10):985-9.

[10] Musaiger AO, Bader Z, Al-Roomi K, et al. Dietary and lifestyle habits amongst adolescents in Bahrain. Food Nutr Res 2011;55:7122.

[11] Yahia N, Achkar A, Abdallah A, et al. Eating habits and obesity among Lebanese university students. Nutr J 2008;7:32.

[12] Bashour HN. Survey of dietary habits of in-school adolescents in Damascus, Syrian Arab Republic. Eastern Mediterranean Health Journal 2004;10(6):853-62.

[13] Sakamaki R, Toyama K, Amamoto R, et al. Nutritional knowledge, food habits and health attitude of Chinese university students: a cross sectional study. Nutr J 2005;4(1):4.

[14] Taveras EM, Berkey CS, Rifas-Shiman SL, et al. Association of consumption of fried food away from home with body mass index and diet quality in older children and adolescents. Pediatrics 2005;116(4):51824.

[15] Malik VS, Willett WC, Hu FB. Global obesity: trends, risk factors and policy implications. Nat Rev Endocrinol 2013;9(1):13-27.

[16] Al-Haj MEA, Awooda HA, Elnimeiri MKM. Eating habits among medical students in a Sudanese medical faculty. Int Res J Med Med Sci 2015;3(3):64-9.

[17] Sawka MN, Cheuvront SN, Carter R III. Human water needs. Nutrition Review 2005;63(6 Pt 2):S30-S9. 